\title{
Prevalence of Microdontia Among Patients Undergoing Orthodontic Treatment
}

\author{
Erum Behroz Khan ${ }^{1}$, Samar Fatima ${ }^{*}$, Syed Muhammad Tariq Rafi ${ }^{1}$, Mairah Shah ${ }^{1}$ and Hafiz Zuhair Ahmed ${ }^{1}$ \\ ${ }^{1}$ Department of Orthodontics, Sindh Institute of Oral Health Sciences, Jinnah Sindh Medical University, Karachi, Pakistan
}

\begin{abstract}
Objective: This study was carried out to determine the prevalence of microdontia among patients undergoing orthodontic treatment.

Materials and Methods: This was a cross-sectional study conducted at Sindh Institute of Oral Health Sciences, Jinnah Sindh Medical University (JSMU) from January-2020 to May-2020. Pre-treatment casts were taken of 140 subjects. The mesiodistal dimension of each tooth was recorded through the vernier caliper. Frequency and percentage were calculated for the presence of microdontia. The test applied was Pearson's Chi-square test to assess the relationship between microdontia and variables like age and gender. P-value <0.05 was taken as statistically significant. Data analysis was performed on SPSS version 22.
\end{abstract}

Results: A total of 140 subjects were selected i.e. 105 (75\%) females and $35(25 \%)$ males with the age range 13-30 years and mean age of $18.29 \pm 3.88$ years. $42(30 \%)$ subjects presented with microdontia. Out of 42 , single tooth microdontia was found in $3(7.1 \%)$, more than one tooth microdontia, and generalized microdontia was present in $36(85.7 \%)$ and $3(7.1 \%)$ respectively. Microdontia was found to be more common in the maxilla $(n=42,100 \%)$ than the mandible $(n=14,33.3 \%)$. It was found more common in females $(n=37,35.2 \%)$ as compared to males $(n=5,14.3 \%)$. Statistically significant relationship was found among gender and prevalence of microdontia ( $p=0.019)$ with a statistically insignificant relationship between age and presence of microdontia $(p=0.228)$.

Conclusion: Microdontia was found to be a frequent dental anomaly, was more common in maxilla and females with a significant association with gender.

Keywords: Microdontia, prevalence, orthodontic treatment.

\section{INTRODUCTION}

Among orthodontic patients, dental anomalies are observed very commonly. An unusually high rate of dental anomalies was recorded in patients seeking orthodontic treatment. Therefore, its management is included in treatment planning by a thorough examination of pre-treatment records. Roslan et al. had found the prevalence of microdontia i.e. $1.08 \%$. The rate is between 0.7 to $12.3 \%$ among orthodontic patients [1]. Fernanda et al. mentioned microdontia $(30.1 \%)$ in Brazilian orthodontic patients [2]. Fekonja A revealed a microdontia prevalence of $2.5 \%$, which is in agreement with the study by Yassin et al. [3, 4]. According to the above studies, the prevalence of microdontia ranges from 0.7 to $30.1 \%$.

Disturbances during the first stage of tooth development can cause abnormalities in tooth shape, size and number. There may be some local or systemic factors responsible for such disturbances. These are esthetically and functionally challenging dental developmental disturbances in size, shape and number that develop before or after birth. Due to these systemic or localized factors, the primary or permanent dentition can be

*Corresponding Author: Samar Fatima, Department of Orthodontics, Sindh Institute of Oral Health Sciences, Jinnah Sindh Medical University, Karachi, Pakistan

Email: sfatima199418@gmail.com

Received: May 15, 2020; Revised: September 07, 2020; Accepted: September 22, 2020 DOI: https://doi.org/10.37184/lnjpc.2707-3521.2.5 affected. Tooth size anomalies can be classified as microdontia or macrodontia $[3,5,6]$. It has been reported that in the majority of the cases microdontia has some genetic basis i.e. it runs in the families but has also been identified spontaneously, with unknown the etiology.

The word microdontia suggests the tooth that is morphologically small in size than normal [7]. Microdontia can be classified into three categories i.e. single tooth microdontia: when only one tooth is smaller than the other teeth e.g. peg-shaped maxillary lateral incisor. Relative microdontia: when comparatively larger jaw contains normal teeth that appear small in a larger jaw. When all the teeth are smaller than usual it is termed as generalized microdontia but, it is a rare condition. The children undergoing chemotherapy or radiotherapy during tooth development has been reported with generalized microdontia. Other causes may include Fanconi's anemia and pituitary dwarfism. The association of microdontia with syndromes has also been reported i.e. Williams's syndrome, RothmundThomson syndrome, Gorlin-Chaudhry-Moss syndrome, Ullrich-Turner syndrome, Orofaciodigital syndrome (type 3), Hallermann Streiff, and a variety of other syndromes.

The lateral incisors in the maxillary arch and the wisdom teeth are the most common teeth affected by microdontia, 
but any of the teeth can be affected. Maxillary permanent lateral incisors that are peg-shaped have prevalence i.e. about $1.8 \%$. Females are frequently affected by maxillary peg-shaped laterals than males and are found more commonly in patients with cleft lip/palate most frequently presence of microdont lateral incisor on the cleft side and in Down's syndromic patients. There has also been some association reported between microdontia and hypodontia i.e. when the patient is microdont there are chances of presence of hypodontia too.

The patients reporting with microdontia have esthetic concerns mainly i.e. they have teeth that are smaller in size than the neighboring teeth or in comparison to other teeth, the presence of space between their teeth. But, the patient can report sometimes concerns regarding functions too that is entrapment of food between teeth due to spaces or malocclusion in microdont individuals [8].

The orthodontist should carefully examine the pretreatment records because these anomalies can cause esthetic and functional compromise among the patient so that their management can be added in treatment planning [2].

The rationale of this study was to find out the frequency of microdontia among patients undergoing orthodontic treatment as the above-mentioned studies have variable results and a wide prevalence range i.e. from $0.7 \%$ to $30.1 \%$, besides there is less evidence reported about the frequency of microdontia in our population. Therefore, its frequency should be identified to aid in early diagnosis and to find out different management options in treatment planning. The objective of the study was to determine the frequency of microdontia among patients undergoing orthodontic treatment.

\section{MATERIALS AND METHODS}

This was a cross-sectional study carried out at Sindh Institute of Oral Health Sciences, (JSMU) from January-2020 to May-2020. Non-probability consecutive sampling technique was used to enroll study participants. By using the WHO sample size calculator for a single population taking reported prevalence as $15.2 \%$ [3], confidence level $95 \%$, margin of error $6 \%$ sample size of the study was calculated as 138. We rounded it off to the nearest ten and enrolled 140 patients. The pre-treatment casts of 140 patients undergoing orthodontic treatment were taken and the mesiodistal dimension of each tooth was recorded with the help of Vernier caliper. The inclusion criteria were that both genders were included, the patients presenting with malaligned teeth and undergoing orthodontic treatment were also included. Exclusion criteria were previous orthodontic treatment, any syndrome, and cleft lip and palate. Ethical approval was taken from the Institutional Review Board of Jinnah Sindh Medical University. This study was conducted on the patients' pre-treatment casts which were taken with written informed consent before commencing orthodontic treatment.

\section{STATISTICAL ANALYSIS}

SPSS version 22 was used to enter the data and its analysis. For age, mean and the standard deviation were calculated. For qualitative variables, frequency and percentage were calculated as for microdontia, gender, maxilla, or mandible. A Chi-square test was applied to assess the association of age and gender with microdontia. P-value $<0.05$ was kept as statistically significant.

\section{RESULTS}

A total of 140 subjects were selected i.e. $105(75 \%)$ females and $35(25 \%)$ males with the age range $13-30$ years and mean age $18.29 \pm 3.88$. Out of 140 subjects, 42 subjects presented with microdontia i.e. the prevalence was $30 \%$ (Fig. 1). Out of 42 , single tooth microdontia was found in $3(7.1 \%)$, more than one tooth microdontia and generalized microdontia was present in $36(85.7 \%)$ and $3(7.1 \%)$ respectively (Fig. 2). All $42(100 \%)$ patients had microdontia in their maxilla while there were $14(33.3 \%)$ who had microdontia in their mandible. The relation between age and the presence of microdontia was found to be statistically insignificant $(p=0.228)$. There was a significant association between the gender of the patient and the presence of microdontia $(p=0.019)$. Microdontia was more common in females $(n=37,35.2 \%)$ as compared to males $(n=5$, 14.3\%) (Table 1).

Table 1: Presence of microdontia, association with age and gender.

\begin{tabular}{c|c|c|c}
\hline $\begin{array}{c}\text { Study } \\
\text { Variables }\end{array}$ & $\begin{array}{c}\text { Microdontia } \\
\text { Frequency (\%) }\end{array}$ & $\begin{array}{c}\text { Normal } \\
\text { Frequency (\%) }\end{array}$ & p-value \\
\hline
\end{tabular}

Age

\begin{tabular}{l|c|c|c}
\hline$\leq 20$ years & $29(27.4)$ & $77(72.6)$ & \\
\hline$>20$ years & $13(38.2)$ & $21(61.8)$ & \\
\hline
\end{tabular}

Gender

\begin{tabular}{l|l|l|l}
\hline Male & $5(14.3 \%)$ & $30(85.7 \%)$ & \\
\hline Female & $37(35.2 \%)$ & $68(64.8 \%)$ & \\
\hline
\end{tabular}




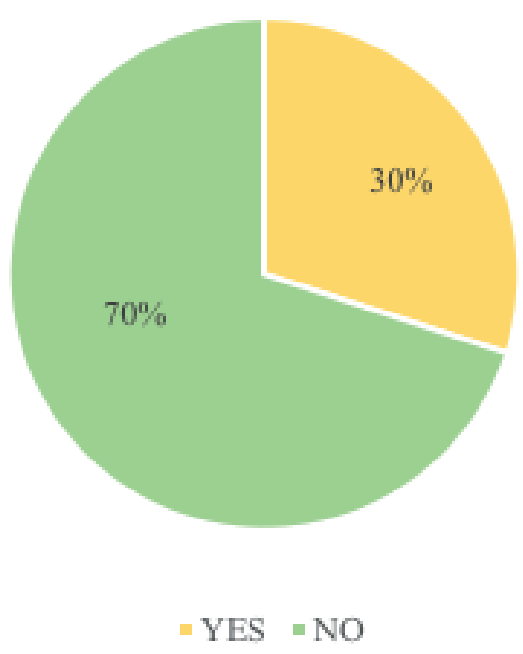

Fig. (1): Prevalence of microdontia, $30 \%$ of the patients had microdontia while it was absent in $70 \%$ of the patients.

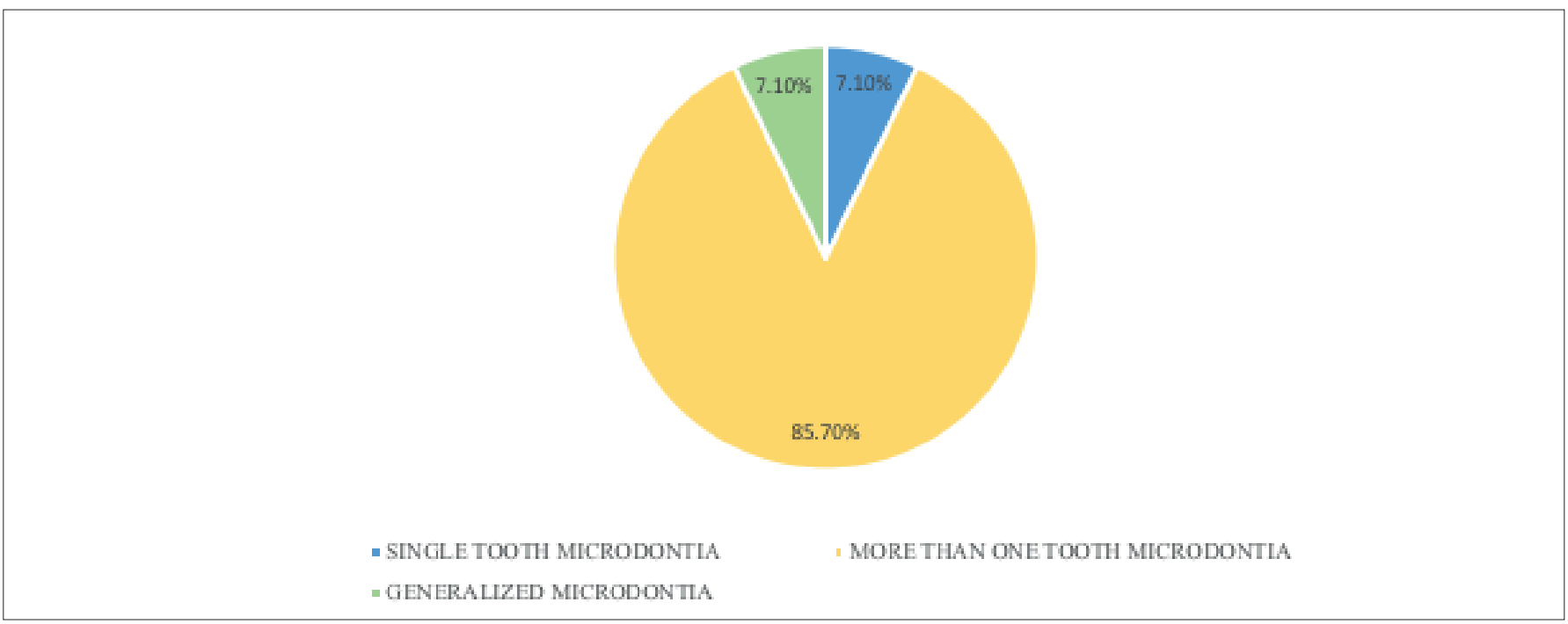

Fig. (2): Presence of microdontia, $7.1 \%$ of patients have single tooth microdontia while generalized microdontia and microdontia of more than one tooth were found in $7.1 \%$ and $85.7 \%$ patients respectively.

\section{DISCUSSION}

Multiple studies have been carried out on dental anomalies but the study regarding this dental anomaly's prevalence is lacking among patients undergoing orthodontic treatment in our population. Therefore, we have done this study to identify the prevalence of a single dental anomaly i.e. microdontia in our target population as a huge number of patients reporting the orthodontists has microdont tooth. A study had found the prevalence of microdontia i.e. $1.08 \%$ [1], another study reported the prevalence of microdontia i.e. $30.1 \%$, and is more common in females [2]. Peg shaped maxillary lateral incisor prevalence i.e. $1.8 \%$ was found in a study and is more common in females [8]. The reported prevalence of microdontia i.e. $2.5 \%$ and more common in females were found also [3]. The prevalence was reported to be $3.08 \%$ in another study [5].

In other studies, the prevalence of microdontia was found to be in the range of $0.54 \%-12.5 \%$ [4, 9-20]. The lateral incisor in the maxilla was the most commonly affected tooth i.e. in the range of $0.6 \%-38.8 \%$ [21-24]. Peg shaped lateral incisor prevalence was found to be $0.1 \%-0.77 \%$ [25-27].

In our investigation, $30 \%$ of the patient-reported with the presence of microdontia. $7.1 \%$ of the patients reported with single tooth microdontia and $7.1 \%$ with generalized microdontia. $85.7 \%$ of patients had microdontia of more than one but less than all teeth microdontia. Among patients who reported with microdontia, $100 \%$ was present in the maxilla and $33.3 \%$ in the mandible with a 
female predominance. The relationship between the presence of microdontia and age was found to be statistically insignificant. The gender and microdontia presence showed a statistically significant relationship.

Our study result supports the previous investigations i.e. microdontia prevalence i.e. $30 \%$ in our population which lies between the range reported in previous studies, more common in maxilla and females.

\section{CONCLUSION}

The results of the present study showed that microdontia was found to be a frequent dental anomaly among patients undergoing orthodontic treatment. Maxilla was affected more than the mandible. Patients reported with microdontia were mostly females indicating that it was more common in females than a male with, no influence of age. By identifying the frequency of this dental anomaly and its early detection alternative treatment modalities can be planned and done to restore the esthetics and function and to avoid any further dental complications in the future.

\section{CONFLICT OF INTEREST}

The authors declare no conflict of interest.

\section{FUNDING}

None.

\section{ACKNOWLEDGEMENTS}

The authors would like to acknowledge the staff in the orthodontic department for their kind assistance in providing materials and facilities for this study.

\section{REFERENCES}

1. Roslan AA, Ab Rahman N, Alam MK. Dental anomalies and their treatment modalities/planning in orthodontic patients. J Orthod Sci 2018; 7: 16

2. de Carli ML, do PG Pedreira R, Ramos PdS, Pedreira MR, Robazza CRC, Hanemann JAC. Association between dental anomalies and malocclusion in Brazilian orthodontic patients. J Oral Sci 2016; 58(1): 75-81.

3. Fekonja A. Prevalence of dental developmental anomalies of permanent teeth in children and their influence on esthetics. J Esthet Restor Dent 2017; 29(4): 276-83.

4. Yassin SM. Prevalence and distribution of selected dental anomalies among Saudi children in Abha, Saudi Arabia. J Clin Exp Dent 2016; 8(5): e485.

5. Bilge NH, Yeşiltepe S, Ağırman KT, Çağlayan F, Bilge OM. Investigation of the prevalence of dental anomalies by using digital panoramic radiographs. Folia Morphol (Warsz) 2018; 77(2): 323-8.
6. Hans MK, Chander S, Ahluwalia AS, Chinna H. Non-syndromic bilateral microdontia of maxillary second molars: a very rare finding. J Clin Diagn Res 2015; 9(4): Zj03-4.

7. Inoue $T$, Saito M, Nishimura $F$, Miyazaki T. Three-dimensional representation of microdontia of the maxillary third molar. Clin Case Rep 2017; 5(4): 547-8.

8. Laverty D, Thomas $M$. The restorative management of microdontia. Br Dent J 2016; 221(4): 160-6.

9. Gupta SK, Saxena P, Jain S, Jain D. Prevalence and distribution of selected developmental dental anomalies in an Indian population. J Oral Sci 2011; 53(2): 231-8.

10. Thongudomporn U, Freer TJ. Prevalence of dental anomalies in orthodontic patients. Aust Dent J 1998; 43(6): 395-8.

11. Aren G, Guven Y, Tolgay CG, Ozcan I, Bayar OF, Kose TE, et al. The prevalence of dental anomalies in a Turkish population. $J$ Istanb Univ Fac Dent 2015; 49(3): 23-8.

12. Sogra Y, Mahdjoube GM, Elham K, Shohre TM. Prevalence of dental anomalies in Iranian orthodontic patients. J Dent Oral Hyg 2012; 4(2): 16-20

13. Al-Jabaa AH, Aldrees AM. Prevalence of dental anomalies in Saudi orthodontic patients. J Contemp Dent Pract 2013; 14(4): 724-30.

14. Altug-Atac AT, Erdem D. Prevalence and distribution of dental anomalies in orthodontic patients. Am J Orthod Dentofacial Orthop 2007; 131(4): 510-4.

15. Ghabanchi J, Haghnegahdar A, Khodadazadeh S, Hagh NS. A radiographic and clinical survey of dental anomalies in patients referring to Shiraz dental school. Shiraz Univ Dent J 2010; 10: 26-31.

16. Vani NV, Saleh SM, Tubaigy FM, Idris A. Prevalence of developmental dental anomalies among adult population of Jazan, Saudi Arabia. Saudi J Dent Res 2016; 7(1): 29-33.

17. Ardakani FE, Sheikhha M, Ahmadi H. Prevalence of dental developmental anomalies: a radiographic study. Community Dent Health 2007; 24(3): 140.

18. Guttal KS, Naikmasur VG, Bhargava P, Bathi RJ. Frequency of developmental dental anomalies in the Indian population. Eur $\mathrm{J}$ Dent 2010; 4(03): 263-9.

19. Dalili Z, Nemati S, Dolatabadi N, Javadzadeh AS, Mohtavipoor ST. Prevalence of developmental and acquired dental anomalies on digital panoramic radiography in patients attending the dental faculty of Rasht, Iran. J Dentomaxillofac Radiol Pathol Surg 2013; 1(2): 24-32.

20. Patil S, Doni B, Kaswan S, Rahman F. Prevalence of dental anomalies in Indian population. J Clin Exp Dent 2013; 5(4): e183.

21. Garib DG, Alencar BM, Lauris JRP, Baccetti T. Agenesis of maxillary lateral incisors, and associated dental anomalies. Am J Orthod Dentofacial Orthop 2010; 137(6): 732. e1-e6.

22. Garib DG, Peck S, Gomes SC. Increased occurrence of dental anomalies associated with second-premolar agenesis. Angle Orthod 2009; 79(3): 436-41. 
23. Herrera-Atoche JR, Diaz-Morales S, Colome-Ruiz G, Escoffie-Ramirez M, Orellana MF. Prevalence of dental anomalies in a Mexican population. Dentistry 3000 2014; 2(1): 1-5.

24. Khan SQ, Ashraf B, Khan NQ, Hussain B. Prevalence of dental anomalies among orthodontic patients. Pak Oral Dental J 2015; 35(2): $224-7$.

25. Saberi EA, Ebrahimipour S. Evaluation of developmental dental anomalies in digital panoramic radiographs in Southeast Iranian Population. J Int Soc Prev Community Dent 2016; 6(4): 291.
26. Salem G. Prevalence of selected dental anomalies in Saudi children from Gizan region. Community Dent Oral Epidemiol 1989; 17(3): 162-3.

27. Sujon MK, Alam MK, Rahman SA. Prevalence of third molar agenesis: associated dental anomalies in non-syndromic 5923 patients. PloS One 2016; 11(8): e0162070. 